\title{
Paper
}

\section{An Approach to Reduce AC LED Flicker}

\author{
Jianchuan TAN and Nadarajah NARENDRAN
}

\section{Lighting Research Center, Rensselaer Polytechnic Institute, Troy, New York, USA}

Received November 14, 2013, Accepted April 21, 2014

\begin{abstract}
In this paper, we investigate a circuit design to reduce light flicker from an alternating current (AC) lightemitting diode (LED) lighting system. AC LEDs in the commercial marketplace have been criticized for the light flicker that they produce. In general, light flicker is an unwelcome phenomenon in a lighting application because of the health hazards it may cause. Some solutions have been proposed to reduce flicker from light sources, but they suffer from issues such as low power factor, low power efficiency, or bulky size. Here we propose an approach that can effectively reduce light flicker from an AC LED lighting system while maintaining normal power factor and high power efficiency.
\end{abstract}

KEYWORDS: AC LED, phase shift, percent flicker, power factor, power efficiency

\section{Introduction}

The alternating current light-emitting diode (AC LED) is a type of solid-state light source that can be directly driven by line voltage, eliminating the need for an external driver to function. The AC LED was introduced to the lighting industry in 2005 , and since then it has experienced rapid development. In today's marketplace, there are basically two types of AC LED. One type consists of two anti-parallel connected micro-LED strings, and the second type uses a bridge rectifier to drive one micro-LED string ${ }^{1-4)}$. The absence of external drivers provides great advantage to AC LEDs, such as smaller system envelope, lower cost, and potentially high system efficiency. Nevertheless, a "congenital" defect, light flicker, is preventing AC LEDs from being widely accepted. Due to the structures of both AC LED types, the sinusoidal oscillation of line voltage causes current fluctuation through the micro-LEDs, which in turn creates periodic change in the light output intensity - that is, light flicker ${ }^{1-3)}$. The existing AC LEDs in today's commercial market produce light flicker at twice the line frequency (e.g., $120 \mathrm{~Hz}$ in North America and $100 \mathrm{~Hz}$ in Europe and China). A number of human factors studies have shown that light flicker with a frequency between 3 and $70 \mathrm{~Hz}$ may cause severe health hazards like epileptic seizures, while light flicker with a frequency between 70 and $160 \mathrm{~Hz}$ can induce eye strain, malaise, dizziness, headache, and so forth ${ }^{5)-10)}$. Several solutions are known to reduce light flicker from lighting systems, such as increasing the driving frequency with a ballast ${ }^{11)-13)}$, and reducing percent flicker by multiphase power system ${ }^{14)-17)}$, or by filtering current ripples through the LEDs ${ }^{4118)}$. But these solutions suffer from drawbacks. The high-frequency driver can increase the driving frequency from $50 / 60 \mathrm{~Hz}$ to tens of $\mathrm{kHz}$, at which human eyes can hardly perceive light flicker, but usually it cannot be integrated with light sources, so an independent envelope is required for it. Even for regular LED drivers with a DC-DC converter, the power loss is not ignorable ${ }^{19)}$; the multi-phase power system also needs an independent envelope. The filtering capacitor can effectively reduce the current ripple through LEDs, but it causes low power factor because the output current waveform is highly distorted ${ }^{488}$. In a power system, power factor is the ratio of input active power to input apparent power ${ }^{20)}$. In the United States, the ENERGY STAR program requires the power factor to be above 0.9 for solid-state luminaires used in commercial applications and above 0.7 for residential ones ${ }^{21}$. Power efficiency is the ratio of the output active power on the load to the input active power of the system ${ }^{2223)}$. Commercial LED drivers available today typically have power efficiency between 80 and $90 \%$ or higher ${ }^{24)-27 \text {. }}$

A human factors study demonstrated that several factors can affect human perception of light flicker, such as frequency, percent flicker (also called modulation depth), waveform, correlated color temperature (CCT), and duty cycle, among which frequency and percent flicker are the two dominant factors ${ }^{2829)}$. In one flicker cycle, the percent flicker is defined as the difference between the maximum and minimum light levels divided by their sum, as is shown in Figure $1^{30}$. Another metric, flicker index, was also proposed to evaluate the perception of light flicker. Flicker index is defined as the ratio of the waveform area above the average light level to the total waveform area in one cycle. Equations 


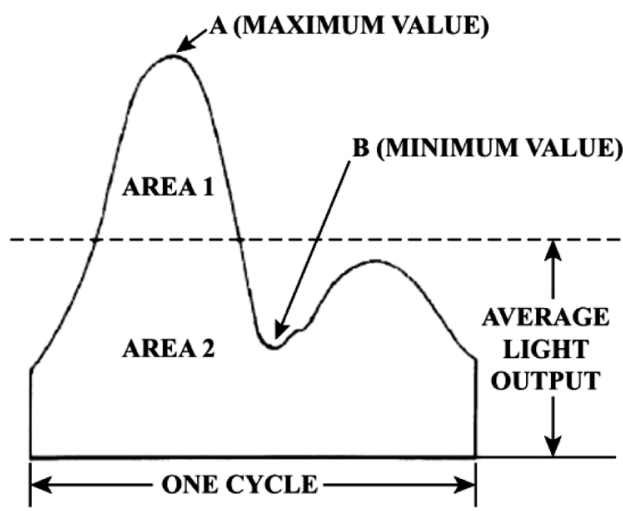

Figure 1 One cycle of flicker waveform ${ }^{30}$

(1) and (2) define percent flicker and flicker index, respectively.

$$
\text { Percent Flicker }=\frac{L_{\max }-L_{\min }}{L_{\max }+L_{\min }} \times 100 \%
$$

$$
\text { Flicker Index }=\frac{\text { Area } 1}{\text { Area } 1+\text { Area } 2}
$$

Another study showed that for some specific waveforms, such as sinusoidal, square, triangular, and sawtooth, flicker index is in positive correlation with percent flicker ${ }^{31}$. Other researchers found that when percent flicker is reduced from 100 to $33 \%$, the acceptability of light flicker can be significantly improved ${ }^{32}$.

In this study, we used percent flicker, instead of flicker index, to evaluate light flicker. Three metrics were used to assess the performance of an AC LED lighting system: percent flicker, power factor, and power efficiency. For percent flicker, its benchmark was set at $33 \%$; for power factor, its benchmark was 0.7 ; and for power efficiency, the benchmark was set at $85 \%$. The objective of this study was to optimize a driving scheme for an AC LED lighting system to keep percent flicker below $33 \%$, power factor above 0.7 , and power efficiency above $85 \%$.

\section{Circuit design and simulation}

A basic principle in electronics states that when a capacitor is driven by a sinusoidal-wave voltage, the current through the capacitor will lead the voltage ${ }^{33)}$. Based on this principle, for this study a circuit with two branches (one resistive and one capacitive) was designed, as shown in Figure 2. In this circuit, Load 1 was driven in the resistive branch (hereafter referred as R-branch), and Load 2 was driven in the capacitive branch (hereafter referred as C-branch). Load 1 was made of two AC LED modules connected in series, while Load 2 consisted of two AC LED modules connected in parallel. Each AC LED module contained two anti-parallel connected highvoltage (HV) LEDs with typical forward voltage of $53 \mathrm{~V}$

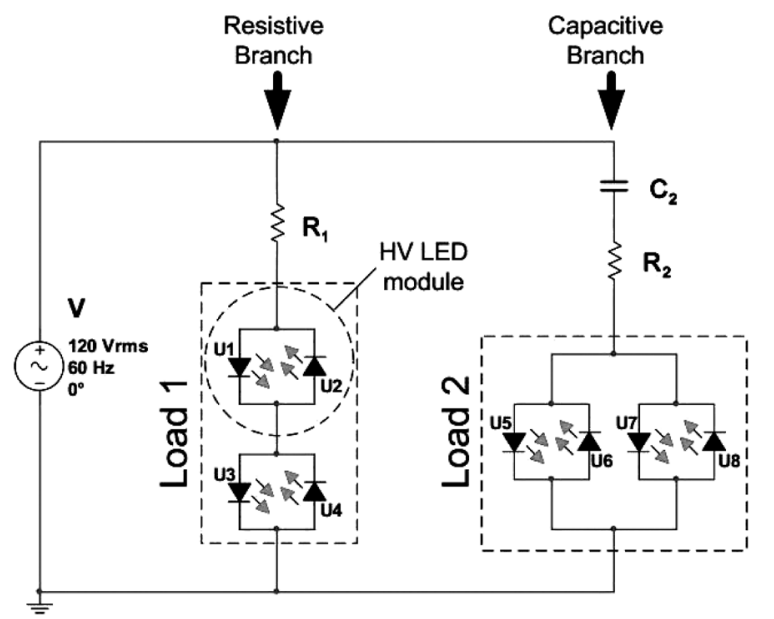

Figure 2 Proposed circuit design of an AC LED lighting system

\section{(ES-AADBHV45 from Epistar Corporation) ${ }^{34)}$.}

For simplicity of calculation, some assumptions were applied to the theoretical simulation: 1) Load 1 and Load 2 were considered as two resistors and their resistances $\left(r_{1}\right.$ and $\left.r_{2}\right)$ were constant in the simulation; 2$)$ the capacitor $\mathrm{C}_{2}$ was purely capacitive; and 3 ) there was no distortion in the voltage and current waveforms of the two loads. A restriction was also applied so that the light output intensities from Load 1 and Load 2 were balanced.

In this study, $R_{1}$ and $R_{2}$ and $C_{2}$ were changeable. Because $R_{1}$ was assumed to be pure resistance, it did not affect the phase shift between the R-branch and the Cbranch. However, the capacitor $\mathrm{C}_{2}$ could produce a phase shift. The changes of $R_{1}, R_{2}$, and $C_{2}$ resulted in changes of percent flicker $(\% \mathrm{~F})$, power factor $(\mathrm{PF})$, and power efficiency $(\eta)$ for this lighting system. This allowed for investigations of the variations of $\% \mathrm{~F}, \mathrm{PF}$, and $\eta$ as functions of phase shift $(\phi)$ between both branches, so that an optimized solution could be identified to meet the three benchmarks.

Theoretical analyses demonstrated that the phase shift $\phi$, percent flicker $\% \mathrm{~F}$, power factor $\mathrm{PF}$, and power efficiency $\eta$ can be expressed as functions of $\mathrm{R}_{1}, \mathrm{R}_{2}$, and $\mathrm{C}_{2}$, as shown in Equations (3)-(6).

Phase Shift: $\phi=\arctan \frac{1}{\omega\left(R_{2}+r_{2}\right) C_{2}}$

Percent Flicker: $\% F=\frac{1-\sin (\phi / 2)}{1+\sin (\phi / 2)}$

Power Factor:

$P F=\cos \left\{\arctan \frac{\frac{R_{1}+r_{1}}{\omega C_{2}}}{\left(R_{1}+r_{1}\right)\left(R_{2}+r_{2}\right)+\left[\left(R_{2}+r_{2}\right)^{2}+\frac{1}{\omega^{2} C_{2}^{2}}\right]}\right\}$ 


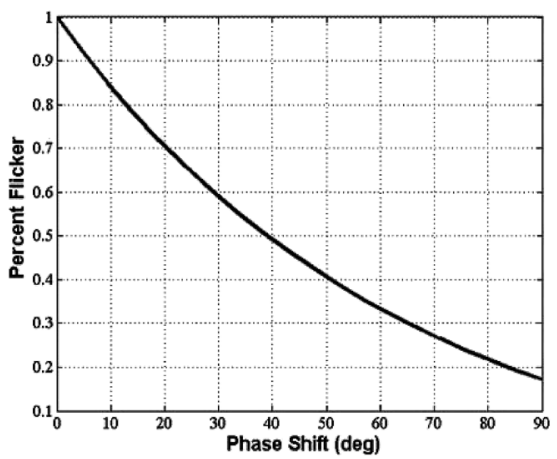

(a)

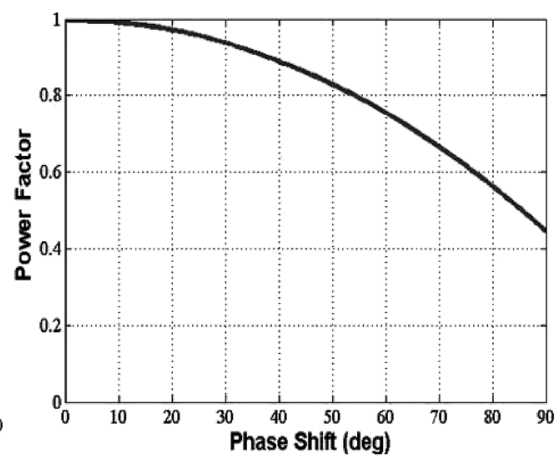

(b)

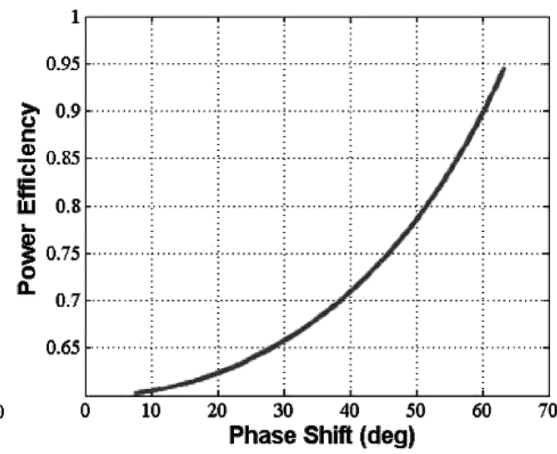

(c)

Figure 3 Simulation results of percent flicker, power factor, and power efficiency as functions of phase shift

Power Efficiency:

$$
\eta=1-\frac{R_{1}\left[\left(R_{2}+r_{2}\right)^{2}+\frac{1}{\omega^{2} C_{2}^{2}}\right]+R_{2}\left(R_{1}+r_{1}\right)^{2}}{\left(R_{1}+r_{1}\right)^{2}\left(R_{2}+r_{2}\right)+\left(R_{1}+r_{1}\right)\left[\left(R_{2}+r_{2}\right)^{2}+\frac{1}{\omega^{2} C_{2}^{2}}\right]}
$$

It was found from Equations (4)-(6) that percent flicker $\% \mathrm{~F}$ can be expressed as an explicit function of phase shift $\phi$, but power factor PF and power efficiency $\eta$ cannot. However, by changing $R_{1}, R_{2}$, and $C_{2}$, a series of corresponding values of $\phi, \% \mathrm{~F}, \mathrm{PF}$, and $\eta$ can be obtained; thus, the variations of $\% \mathrm{~F}, \mathrm{PF}$, and $\eta$ as functions of $\phi$ can be identified, as presented in Figure 3. Three theoretical results were identified from Figure 3 showing that when phase shift $\phi$ increased, percent flicker $\% \mathrm{~F}$ and power factor $\mathrm{PF}$ decreased, but power efficiency $\eta$ increased.

\section{Experiment and results}

An experiment was conducted to verify the theoretical analyses and to investigate an optimal solution for this circuit design. Figure 4 illustrates the experiment setup. The apparatus included:

-A white, non-luminescent matte painted box with a photodiode for combining the light output from Load 1 and Load 2, as well as to avoid ambient light;

-Two switches, K1 and K2, and a photometer to balance the light output from both loads;

- Two rheostats, $R_{1}$ and $R_{2}$, and a variable $A C$ capacitor, $\mathrm{C}_{2}$;

-A powermeter (YOKOGAWA WT200) to measure the input active power and the power factor of the whole system;

-Two current monitors to take current waveforms through both loads;

-An oscilloscope (Tektronix TDS 3014C) to take waveforms of voltage across both loads and the waveforms of current through both loads, for calcu-

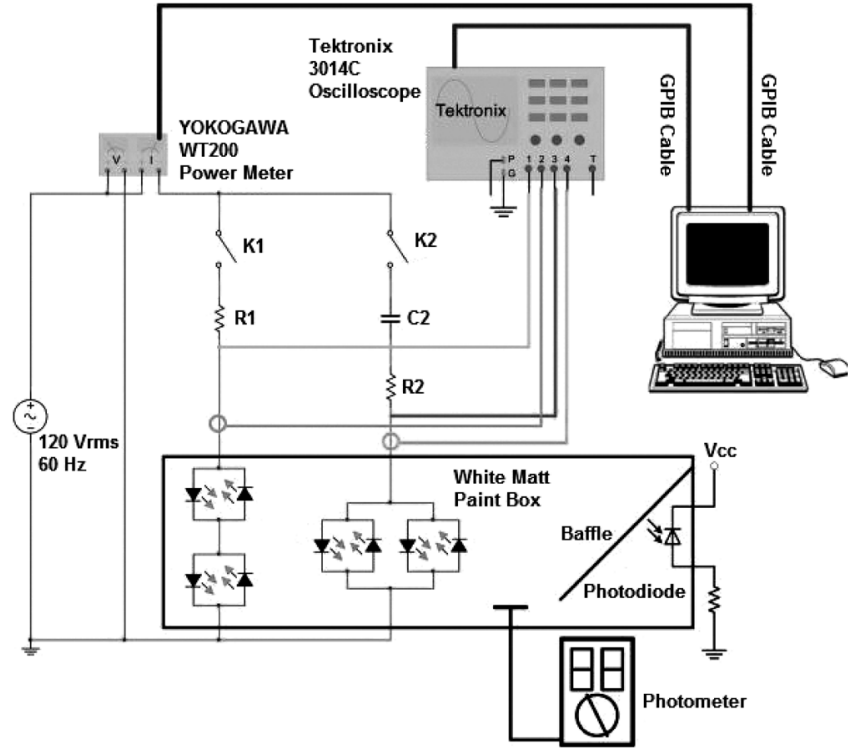

Figure 4 Setup of the experiment

lating phase shift $\phi$ and the output active power on both loads;

- A computer for collecting and analyzing the data.

In the experiment, $\mathrm{R}_{1}$ was fixed at $600 \Omega$ so that the RMS current through Load 1 was about $20 \mathrm{~mA}$, which is the rated current for the HV LEDs in use. While keeping $\mathrm{R}_{1}$ fixed, $\mathrm{R}_{2}$ and $\mathrm{C}_{2}$ were adjusted to produce different phase shifts between the R-branch and the Cbranch. Here the RMS current through Load 2 was maintained at about $40 \mathrm{~mA}$, twice the amount of current in Load 1. The two AC LED modules in Load 1 and Load 2 were connected in series and in parallel, respectively. To balance the light outputs from both loads, the RMS current in Load 2 should be twice that in Load 1.

The experimental results are shown in Figure 5. In order to confirm the variations of $\% \mathrm{~F}, \mathrm{PF}$, and $\eta$, linear fittings were conducted to show that with $95 \%$ confidence, the experimental variations were consistent with the theoretical predictions. 
Table 1 Electrical component values and corresponding power data, at $\mathrm{R}_{1}=600 \Omega$

\begin{tabular}{|c|c|c|c|c|c|c|c|c|c|}
\hline $\mathrm{C}_{2}(\mu \mathrm{F})$ & $\mathrm{R}_{2}(\Omega)$ & $\phi(\mathrm{deg})$ & $\begin{array}{c}\text { Power in } \\
\text { Load 1 (W) }\end{array}$ & $\begin{array}{c}\text { Power in } \\
\text { Load 2 (W) }\end{array}$ & $\begin{array}{c}\text { Output } \\
\text { power (W) }\end{array}$ & $\eta$ & $\begin{array}{c}\text { Input } \\
\text { power (W) }\end{array}$ & $\begin{array}{c}\text { Apparent } \\
\text { power (VA) }\end{array}$ \\
\hline 2.122 & 311 & 55 & 2.043 & 2.116 & 4.159 & 0.753 & 5.523 & 0.824 & 6.703 \\
\hline 2.080 & 211 & 60 & 2.097 & 2.173 & 4.270 & 0.783 & 5.454 & 0.781 & 6.983 \\
\hline 2.065 & 151 & 62 & 2.102 & 2.204 & 4.306 & 0.812 & 5.303 & 0.749 & 7.080 \\
\hline 2.056 & 128 & 63 & 2.105 & 2.207 & 4.312 & 0.833 & 5.177 & 0.747 & 6.930 \\
\hline 2.050 & 81 & 65 & 2.116 & 2.222 & 4.337 & 0.840 & 5.163 & 0.733 & 7.044 \\
\hline 2.037 & 50 & 67 & 2.121 & 2.231 & 4.352 & 0.872 & 4.991 & 0.714 & 6.990 \\
\hline
\end{tabular}

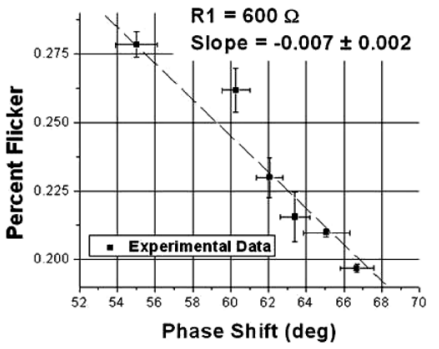

(a)

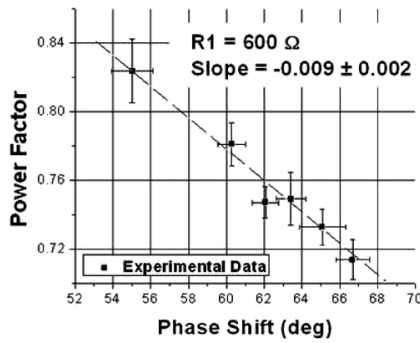

(b)

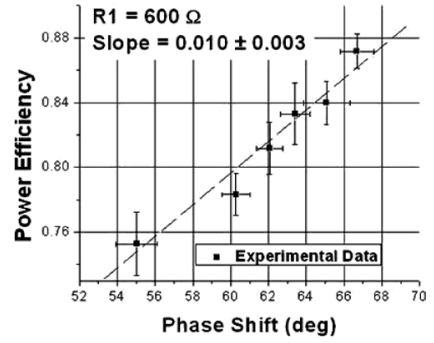

(c)

Figure 5 Experimental variations of (a) percent flicker \%F, (b) power factor PF, and (c) power efficiency $\eta$ as functions of phase shift $\phi$

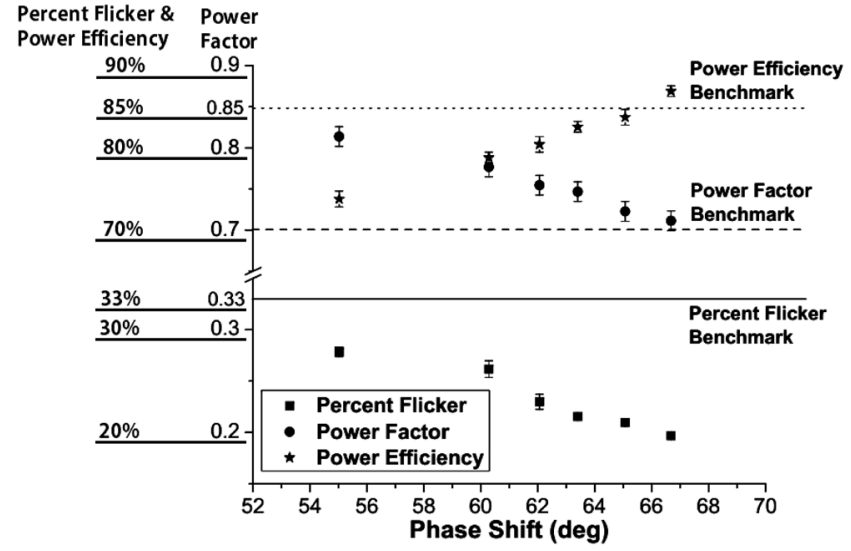

Figure 6 Performance of the circuit design in the experiment, including phase shift, power factor, and power efficiency

The performance of the circuit design in the experiment is illustrated in Figure 6, from which it can be found that with a phase shift $\phi$ between $66^{\circ}$ and $68^{\circ}$, an optimized solution can be achieved to meet the benchmarks of percent flicker $\% \mathrm{~F}<33 \%$, power factor $\mathrm{PF}>0.7$, and power efficiency $\eta>85 \%$. Figure 7 demonstrates the waveforms of current that flow through Load 1 and Load 2, as well as the intensity of total light output at the phase shift of $67^{\circ}$.

The values of electrical components and power data are listed in Table 1 . The input power is around 5 watts,

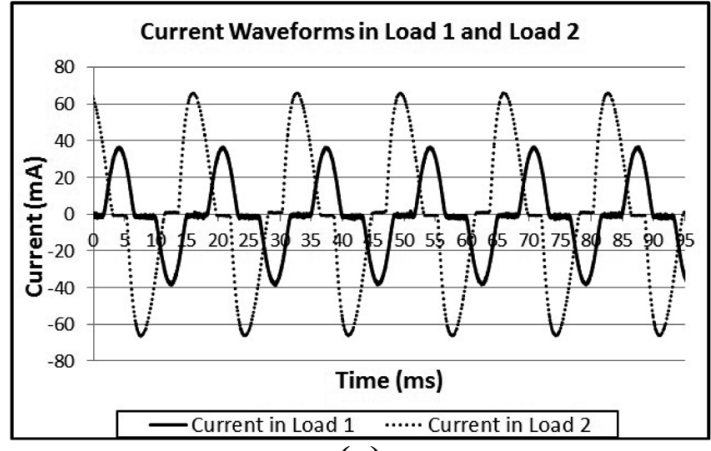

(a)

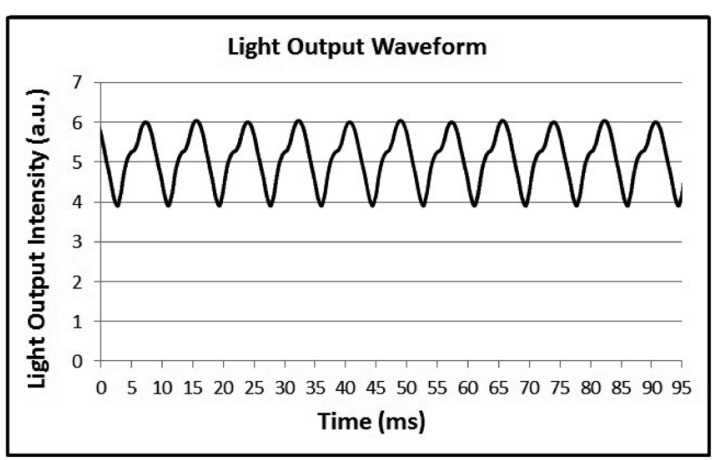

(b)

Figure 7 (a) Current waveforms in Load 1 and Load 2, and (b) waveform of the total light output from Load 1 and Load 2, at phase shift of $67^{\circ}$ 
which is suitable for residential use.

\section{Discussion}

To simplify the theoretical analysis, it was assumed that the HV LED is a linear component (current-voltage relationship is linear), which is not true in the entire voltage range. However, the main purpose of the theoretical analysis was to predict how the phase shift changes with electrical component values and how the dependent variables (percent flicker, power factor, and power efficiency) change as a function of phase shift. It was not meant to derive exact values of the dependent variables. The theoretical and the experimental results show similar trends in the percent flicker, power factor, and power efficiency change as a function of phase shift, indicating the validity of the assumption for the intended analysis.

The advantages of this circuit design include: 1) significantly reduced light flicker compared with existing AC LED products in the market; 2) potentially higher reliability than existing AC LED products, owing to very simple circuit design and much fewer components compared with existing LED lighting systems; 3) very low cost of driving components (resistor and capacitor) and simplicity of replacement if any driving component fails; 4) lower power loss during current conduction in wires and soldering, owing to the usage of high-voltage and low-current LEDs.

A big tradeoff in this circuit design is between power factor and power efficiency. As one can see in Figure 6, power factor and power efficiency vary in opposite directions as phase shift changes, meaning that when one seeks high efficiency, power factor will be sacrificed, and vice versa. Additionally, the component values in both branches are correlated; for example, when $\mathrm{R}_{2}$ changes, in order to balance the light outputs from both loads, $\mathrm{R}_{1}$ should also change.

The main disadvantage of such a circuit is the difficulty involved in designing optics to redistribute the light. Due to the large emitting area, achieving a uniform light distribution with this circuit design will become a new topic of future research.

\section{Summary}

The proposed circuit design was shown to successfully reduce light flicker from an AC LED lighting system. The circuit contained a resistive branch and a capacitive branch, and each branch drives a load made up of high-voltage LEDs. Based on this circuit design, an optimized scheme was achieved to maintain normal power factor and high power efficiency.

\section{Acknowledgments}

This study was funded by the Federal Aviation Ad- ministration (FAA Cooperative Agreement 10-G-013), the Alliance for Solid-State Illumination Systems and Technologies (ASSIST), and the Lighting Research Center at Rensselaer Polytechnic Institute. We would like to thank Andrew Bierman, Yiting Zhu, Terry Klein, YiWei Liu, Martin Overington, John Bullough, Howard Ohlhous, and Jennifer Taylor at the Lighting Research Center for their enlightening discussions and kind assistance in this study.

\section{References}

(1) Yeh, W.-Y., Yen, H.-H. and Chan, Y.-J.: The development of monolithic alternating current light-emitting diode, Proc. SPIE, Vol. 7939, pp. 793910-1-12 (2011).

(2) Wilkins, A., Veitch, J. and Lehman, B.: LED lighting flicker and potential health concerns: IEEE standard PAR1789 update, Energy Conversion Congress and Exposition (ECCE), pp. 171-178 (2010).

(3) A Review of Literature on Light Flicker: Ergonomics, Biological Attributes, Potential Health Effects, and Methods in Which Some LED Lighting May Introduce Flicker, IEEE Standard 1789, Feb. 26, (2010).

(4) Seoul Semiconductor: Application Note: Designing with Acriche A4 (2011), Online: http://www.seoul semicon.com/_upload/Goods_Spec/A4_Applica tionnote.pdf (Accessed Oct. 29, 2013).

(5) Fisher, R. S., Harding, G., Erba, G., Barkley, G. L. and Wilkins, A.: Photic- and pattern-induced seizures: A review of the epilepsy foundation of America working group, Epilepsia, Vol. 46(9), pp. 1426-1441 (2005).

(6) Binnie, C. D., de Korte, R. A. and Wisman, T.: Fluorescent lighting and epilepsy, Epilepsia, Vol. 20(6), pp. 725-727 (1979).

(7) Wilkins, A. J.: Intermittent illumination from visual display units and fluorescent lighting affects movements of the eyes across text, Human Factors, Vol. 28(1), pp. 75-81 (1986).

(8) Wilkins, A. J., Nimmo-Smith, I., Slater, A. I. and Bedocs, L.: Fluorescent lighting, headaches and eyestrain, Lighting Res. \& Technol., Vol. 21(1), pp. 1118 (1989).

(9) Harding, G. F. A. and Jeavons, P.: Photosensitive Epilepsy. London, UK, Mac Keith Press (1994).

(10) Wilkins, A. J.: Visual Stress. New York, NY, Oxford University Press (1995).

(11) Lynk Labs, Inc.: Specifications of BriteDriver ${ }^{\circledR}$ BD60W-120V/12V (2011), Online: http://www. lynklabs.com/images/BD60W-120V-12V\%20 Data\%20Sheet,\%20Issue\%201,\%20January,\%202011. pdf (Accessed Oct. 29, 2013).

(12) Mulay, A., Trivedi, M., Vijayalakshmi, R. and Shenai, K.: Switching dynamics of power bipolar tran- 
sistor in high-frequency electronic ballast, IEEE Ind. Applicat. Conf., Vol. 3, pp. 2130-2136 (1998).

(13) Zhu, P. and Hui, S. Y. R.: Modelling of a high-frequency operated fluorescent lamps in an electronic ballast environment, IEE Proc. Sci. Meas. Technol., Vol. 145(3), pp. 111-116 (1998).

(14) Kolesar, P. M. and Payne, R.: Non-flickering display system having multi-phase power source, U.S. Patent 3728 714, Apr. 17 (1973).

(15) Chang, Y. N., Lam, C. S., Moo, C. S. and Yen, H. C.: Electric ballast with multi-phase outputs for fluorescent lighting, IEEE Power Electron. and Drives Syst., Vol. 1, pp. 811-815 (2005).

(16) Doshi, M. and Zane, R.: Control of solid-state lamps using a multiphase pulsewidth modulation technique, IEEE Trans. Power Electron, Vol. 25, No. 7, pp. 1894-1904 (2010).

(17) Chen, P.-R.: Flickering phenomenon study of AC LED based on multi-phase power supplies, M. S. thesis, Dept. of Elect. Eng., Natl. Taiwan Univ., Taiwan (2011).

(18) Li, Y., Liu, Y., Boonekamp, E. P., Shi, L., Mei, Y., Jiang, T., Guo, Q. and Wu, H.: LED solution for E14 candle lamp, Proc. SPIE, Vol. 7422, pp. 74220T-1-12 (2009).

(19) Wang, Z., Gu, Y. and Xie, S.: Study of high power AC-LED based on the structure of composite bridge with SMD packaging, Proc. SPIE, Vol. 7659, pp. 76590D-1-7 (2010).

(20) Wolsey, R: Power Quality (1995), Online: http:// www.lrc.rpi.edu/programs/NLPIP/publicationdetails.asp?id=123\&type $=2$ (Accessed Oct. 29, 2013).

(21) U. S. Department of Energy: ENERGY STAR ${ }^{\circledR}$ program requirements for luminaires, Version 1.2 (2011), Online: http://www.energystar.gov/products/ specs/sites/products/files/Final_Luminaires_ V1_2_1.pdf (Accessed Oct. 29, 2013).

(22) The IEEE Standard Dictionary of Electrical and Electronics Terms, 6th ed., IEEE Std-100 (1996).

(23) Winder, S.: Thermal considerations, Power Supply for LED Driving, 1st ed., Burlington, MA, Newnes, pp. 217-223 (2008).

(24) OSRAM: OPTOTRONIC ${ }^{\circledR}$ electronic constant current LED power supplies (2008), Online: http:// www.newark.com/pdfs/datasheets/Osram/OPTO
TRONIC.pdf (Accessed Oct. 29, 2013).

(25) OSRAM: OPTOTRONIC ${ }^{\circledR}$ technical guide: Electronic power supplies for LED-modules (2009). Online: http://www.osram.hu/_global/pdf/Professional/ ECG_\%26_LMS/ECG_for_LED/OPTOTRONIC_ Technical_Guide130T008GB.pdf (Accessed Oct. 29, 2013).

(26) PHILIPS: Xitanium/Fortimo LED drivers indoor (2012), Online: http://download.p4c.philips.com/ $14 \mathrm{bt} / 3 / 333198 /$ xitaniumfortimo_led_drivers_ indo_333198_ffs_aen.pdf (Accessed Oct. 29, 2013).

(27) National Semiconductor: LED drivers for highbrightness lighting (2011), Online: http://www.ti. com/lit/sl/snvy001/snvy001.pdf (Accessed Oct. 29, 2013).

(28) Bullough, J. D., Sweater Hickcox, K., Klein, T. R. and Narendran, N.: Effects of flicker characteristics from solid-state lighting on detection, acceptability and comfort, Lighting Res. Technol., Vol. 43, pp. 337-348 (2011).

(29) ASSIST: Flicker parameters for reducing stroboscopic effects from solid-state lighting systems (2010), Online: http://www.lrc.rpi.edu/programs/ solidstate/assist/pdf/AR-Flicker.pdf (Accessed Oct. 29, 2013).

(30) Rea, M. S., ed.: IESNA Lighting Handbook, 9th ed., New York, NY, IESNA Publications (2000).

(31) Paget, M., Poplawski, M. and Russell, B.: CALiPER exploratory study: Flicker in SSL integral replacement lamps, presented at CORM Conference, Gaithersburg, MD, USA, May 5, 2011.

(32) Bullough, J. D., Sweater Hickcox, K., Klein, T. R., Lok, A. and Narendran, N.: Detection and acceptability of stroboscopic effects from flicker, Lighting Res. \& Technol., Vol. 44(4), pp. 477-483 (2012).

(33) Horowitz, P. and Hill, W.: The Art of Electronics, 2nd Edition, Cambridge, UK, Cambridge University Press, pp. 34, 44 (1980).

(34) Epistar Corporation: Specifications of ES-AADBHV45. Confidential information from Epistar Corp. (2011).

Part of this work was presented in the session of LED-based Illumination System, SPIE Optics+Photonics conference, August, 2013, San Diego, CA, USA. 